\title{
Temporal Progression of 'Candidatus Liberibacter asiaticus' Infection in Citrus and Acquisition Efficiency by Diaphorina citri
}

\author{
Helvecio D. Coletta-Filho, Matthew P. Daugherty, Cléderson Ferreira, and João R. S. Lopes
}

First author: Centro de Citricultura Sylvio Moreira, IAC, Cordeirópolis, SP, 13490-970, Brazil; second author: Department of Entomology, University of California, Riverside; and third and fourth authors: Department of Entomology and Acarology, ESALQ/Universidade de Sao Paulo, Piracicaba, SP 13418-900, Brazil.

Accepted for publication 26 October 2013.

\begin{abstract}
Coletta-Filho, H. D., Daugherty, M. P., Ferreira, C., and Lopes, J. R. S. 2014. Temporal progression of 'Candidatus Liberibacter asiaticus' infection in citrus and acquisition efficiency by Diaphorina citri. Phytopathology 104:416-421.

Over the last decade, the plant disease huanglongbing (HLB) has emerged as a primary threat to citrus production worldwide. HLB is associated with infection by phloem-limited bacteria ('Candidatus Liberibacter' spp.) that are transmitted by the Asian citrus psyllid, Diaphorina citri. Transmission efficiency varies with vector-related aspects (e.g., developmental stage and feeding periods) but there is no information on the effects of host-pathogen interactions. Here, acquisition efficiency of 'Candidatus Liberibacter asiaticus' by $D$. citri was evaluated in relation to temporal progression of infection and pathogen titer in citrus. We graft

times after inoculation, we inspected plants for HLB symptoms, measured bacterial infection levels (i.e., titer or concentration) in plants, and measured acquisition by psyllid adults that were confined on the trees. Plant infection levels increased rapidly over time, saturating at uniformly high levels $\left(\approx 10^{8}\right.$ copy number of $16 \mathrm{~S}$ ribosomal DNA/g of plant tissue) near 200 days after inoculation - the same time at which all infected trees first showed disease symptoms. Pathogen acquisition by vectors was positively associated with plant infection level and time since inoculation, with acquisition occurring as early as the first measurement, at 60 days after inoculation. These results suggest that there is ample potential for psyllids to acquire the pathogen from trees during the asymptomatic phase of infection. If so, this could limit the effectiveness of tree rouging as a disease management tool and would likely explain the rapid spread observed for this disease in the field.
\end{abstract} inoculated sweet orange trees with ' $\mathrm{Ca}$. L. asiaticus'; then, at different
Under favorable environmental conditions for plant disease expression, the various interactions among a virulent pathogen, one or more susceptible hosts, and vectors make understanding and managing vector-borne diseases an inherently complex task (1). Numerous studies have considered the transmission of plant pathogens by vectors as being paramount to understanding disease dynamics and developing management strategies, particularly for plant viruses $(13,15,33)$. To date, far fewer studies have elucidated the transmission dynamics for plant-pathogenic bacteria (2).

Huanglongbing (HLB) is a disease associated with noncultivated $\alpha$-proteobacteria known as liberibacters, which affect all citrus varieties and many related species in the family Rutaceae. These phloem-limited pathogens have caused substantial economic losses by affecting productivity and fruit quality and shortening the life span of infected trees (18). Although three 'Candidatus Liberibacter' spp. are associated with the disease ('Candidatus Liberibacter africanus', ' $\mathrm{Ca}$. L. asiaticus', and ' $\mathrm{Ca}$. L. americanus'), the Asian ' $\mathrm{Ca}$. L. asiaticus' is the most prevalent throughout HLB-affected citrus-growing areas in Asian countries, Brazil, the United States, and, recently, in several Central American countries $(7,17)$. The rapid spread of disease in those recently affected regions appears to be related to the establishment and spread of ' $C a$. L. asiaticus' by an important vector species, the Asian citrus psyllid (ACP), Diaphorina citri Kuwayama (Hemiptera: Liviidae).

Corresponding author: H. D. Coletta-Filho;

E-mail address: helvecio@centrodecitricultura.br

http://dx.doi.org/10.1094/PHYTO-06-13-0157-R

(c) 2014 The American Phytopathological Society
HLB was first detected in Sao Paulo State, Brazil, in 2004, and has since spread throughout most of the state, primarily associated with movement by the vector (5). Rapid spread of the disease also occurred in Florida, after the first detection in 2005, and later in other southeastern states of the United States (17). Most recently, HLB has become established in parts of Texas, and at least one case has been found in California.

The management of HLB varies regionally but generally relies on a combination of approaches, including removal of diseased trees or nutritional programs to minimize disease severity, largescale production of clean nursery stock in insect-proof screenhouses, and aggressive vector control (i.e., biological control and, especially, chemical control). Yet, despite these management efforts, their success remains uncertain $(5,17)$. In important citrusgrowing areas such as Sao Paulo State, Brazil and Florida, HLB prevalence and vector pressure remain high. A better understanding of the transmission ecology of ' $\mathrm{Ca}$. L. asiaticus' by $\mathrm{D}$. citri is needed to develop control strategies that effectively and sustainably reduce disease incidence-particularly for regions where the disease is not yet widespread (i.e., California). Yet, important aspects of pathogen transmission and epidemiology in this system remain unresolved, which has hampered efforts to refine existing control strategies.

Both ACP adults and nymphs can transmit ' $\mathrm{Ca}$. L. asiaticus' (24). The bacterium acquired by nymphs can be retained and transmitted after emergence of adults (8), suggesting that the pathogen circulates in the psyllid vector. Recent studies present evidence that the pathogen multiplies in the vector following acquisition (25) and is distributed in various internal organs, with accumulation in the alimentary canal and salivary glands $(3,4)$. Higher acquisition and inoculation rates are generally observed when the pathogen is acquired in the nymphal stage than as adults 
$(25,31)$ but reported transmission efficiencies are highly variable among the studies. For instance, Pelz-Stelinski et al. (31) in Florida found a mean transmission efficiency of only $5 \%$ by single ACP adults that were reared during the whole nymphal stage on ' $\mathrm{Ca}$. L. asiaticus'-infected plants, whereas Inoue et al. (25) in Japan obtained successful inoculation to most (66\%) test plants by groups of three adults that had been exposed as nymphs to infected plants for just $24 \mathrm{~h}$. Variable transmission rates by ACP were also reported in older studies carried out in Taiwan (1.3\%) (23) and China (80\%) (38).

The discrepancy in ' $\mathrm{Ca}$. L. asiaticus' transmission efficiencies among various studies could be an artifact of different experimental conditions used in the transmission assays (e.g., number of insects per test plant, duration of acquisition and inoculation access periods, and variety or physiology of citrus used as source or test plants) or sensitivity of pathogen detection methods, as well as other factors such as the origin and strain of the pathogen or genotypic differences in vector efficiency between the ACP populations tested $(25,31)$. Another likely explanation is that there are underlying differences in pathogen infection level (i.e., bacterial titer or concentration) in the host plants used as inoculum sources, which may affect acquisition efficiency. Despite recent attempts to elucidate the determinants of ' $\mathrm{Ca}$. L. asiaticus' transmission by ACP, little work has been done to relate ' $\mathrm{Ca}$. L. asiaticus' reservoir competence in citrus plants to vector acquisition of the pathogen.

The primary objective of this study was to investigate acquisition efficiency of ' $C a$. L. asiaticus' by $D$. citri adults over a gradient in bacterial titer in infected citrus plants. We documented the temporal progression of ' $\mathrm{Ca}$. L. asiaticus' infection and HLB symptom onset in graft-inoculated nursery trees and the ensuing impacts on psyllid transmission. These measures allow for estimation of the relative duration of incubation period (i.e., time to first symptoms), host latent period for acquisition (time to become a source of the pathogen [i.e., infectiousness]), and the host infection level required for successful pathogen acquisition.

\section{MATERIALS AND METHODS}

Psyllid rearing. Noninfectious D. citri individuals originally collected in Piracicaba, SP, Brazil, were reared on young flush of potted Murraya paniculata (L.) Jack (Rutaceae), which is an optimal rearing host for this insect (36). The colony was maintained inside screened cages in a climate-controlled room $\left(25 \pm 2{ }^{\circ} \mathrm{C}\right.$, $70 \pm 10 \%$ relative humidity, and photoperiod of $14 \mathrm{~h}$ of light and $10 \mathrm{~h}$ of darkness) under fluorescent light bulbs (80 W), as described by Bonani et al. (6).

Graft inoculation of source trees. Sixty 5-month-old sweet orange (Citrus sinensis (L.) Osbeck, 'Pera') nursery trees grafted on 'Rangpur lime' ( $C$. limonia Osbeck) rootstock were graft inoculated at the same time with two ' $\mathrm{Ca}$. L. asiaticus'-infected budwood sticks ( 2 to $3 \mathrm{~cm}$ long), which were grafted on opposite sides of the sweet orange primary stem. These infected sticks were collected from an HLB-symptomatic tree kept in an insectproof greenhouse. Groups of four to six independent nursery trees were used as sources for psyllid acquisition assays at 60, 130, $145,165,180,200,235$, and 280 days after graft inoculation (DAI), when shoots with developing leaves were present in at least four plants. One sweet orange tree of the same age and variety was graft inoculated with healthy budwood and used as a negative control for each acquisition assay, whereas one HLBsymptomatic tree (older than the tested ones) was used as a positive control. All the experimental plants were produced in 4-liter plastic bags containing Plantmax Citrus substrate (Eucatex, Itapetininga, SP, Brazil) and were maintained in an insect-proof greenhouse at Centro de Citricultura, Cordeiropolis, Sao Paulo, Brazil, with temperatures of 20 to $30^{\circ} \mathrm{C}$ during the period of the acquisition assays (September 2008 to June 2009). The source trees were automatically drip irrigated every day, fertilized when necessary, and monitored weekly for HLB symptoms. Groups of six source trees were pruned at 2- or 3-week intervals after 3 months following graft inoculation, in order to obtain shoots of similar age to be used in the acquisition assays. Source plant height before pruning varied from 55 to $75 \mathrm{~cm}$.

Pathogen acquisition and transmission assays. In each of the eight different times since budwood infection (DAI), groups of 70 to 120 lab-reared noninfectious $D$. citri adults were confined on young shoots of each source tree (inside mesh sleeve cages) for an acquisition access period (AAP) of 7 days, then caged for a 21-day vector latent period on four healthy sweet orange ('Caipira') seedlings, $\approx 20 \mathrm{~cm}$ high, which were grown in 0.2 -liter pots with Plantmax Citrus substrate inside an insect-proof screenhouse. After the latency, the group of psyllids from each source tree was transferred to new healthy sweet orange seedlings but subdivided into groups of three psyllids per seedling test plant, on which they were confined inside plastic leaf cages for an inoculation access period (IAP) of 7 days. The number of inoculated test plants per group of psyllids from each source tree was 2 to 38. After the IAP, psyllids were collected, stored in $100 \%$ alcohol at $-20^{\circ} \mathrm{C}$, and tested at a later date for ' $\mathrm{Ca}$. L. asiaticus' infection by quantitative polymerase chain reaction (qPCR) in groups of three insects per sample ( $n=1$ to 27 samples per source tree).

Acquisition efficiency was estimated via the proportion of qPCR-positive psyllid samples over the total number of samples tested per source tree. As a second measure of vector efficiency, we evaluated the infection status of the test plants exposed to the groups of three psyllids. These exposed test seedlings were held in a vector-proof screenhouse for 12 months for pathogen replication and symptom development prior to testing for the presence of ' $\mathrm{Ca}$. L. asiaticus' by qPCR. The transmission efficiency was estimated by the number of qPCR-positive seedlings over the total number tested.

DNA extraction. We used the cetyltrimethylammonium bromide (CTAB)-based method (30) for DNA extraction from plants. Samples consisted of sections $(\approx 200 \mathrm{mg})$ of four leaf petioles selected from the caged shoots on which the psyllids fed during the AAP in the case of source plants and from different branches in the case of test plants. Source plants were sampled right after the AAP. Initially, the petioles of each sample were finely cut and placed in 2-ml tubes with 5-mm stainless steel beads and $625 \mu \mathrm{l}$ of buffer (100 mM Tris [pH 8.0], $50 \mathrm{mM}$ EDTA, and $500 \mathrm{mM}$ $\mathrm{NaCl})$. Tissue was disrupted using TissueLyser II system homogenizer (Qiagen, Valencia, CA) at speed $30 \mathrm{~Hz}$ for $120 \mathrm{~s}$; then, $725 \mu \mathrm{l}$ of buffer 2 (CTAB, 5\%; Sarcosyl, 10\%; and $10 \mathrm{mM}$ $\mathrm{B}$-mercaptoethanol) was added to the tube. The total DNA was resuspended at $400 \mu \mathrm{l}$ of 1/10 Tris-EDTA (TE) + RNase.

For DNA extraction from psyllids, the samples of three insects were crushed by the TissueLyser II system using 3-mm stainless steel beads and $100 \mu \mathrm{l}$ of STE buffer $(10 \mathrm{mM}$ Tris- $\mathrm{HCl}, 1 \mathrm{mM}$ EDTA, and $25 \mathrm{mM} \mathrm{NaCl}$ ) into $500-\mu$ l tubes, which were shaken at $20 \mathrm{~Hz}$ for $60 \mathrm{~s}$. Following homogenization, $15 \mu \mathrm{l}$ of proteinase $\mathrm{K}(200 \mu \mathrm{g} / \mathrm{ml})$ was added and the tubes were incubated at $56^{\circ} \mathrm{C}$ for $30 \mathrm{~min}$. DNA was purified by using the Wizard Genomic DNA Purification kit (Promega Corporation, Madison, WI). The total DNA was resuspended in $50 \mu \mathrm{l}$ of $1 / 10 \mathrm{TE}+\mathrm{RNase}$.

qPCR assay. The presence of ' $\mathrm{Ca}$. L. asiaticus' in plant and psyllid samples was determined by real-time PCR amplifications using sets of $16 \mathrm{~S}$ ribosomal DNA (rDNA) primers and FAM/Iowa Black FQ label probe (IDT Inc., Coralville, IA), as described by Coletta-Filho et al. (10). The ' $C a$. L. asiaticus' quantification (copy number $[\mathrm{CN}]$ of $16 \mathrm{~S}$ rDNA per gram of citrus tissue) was based on the formula $y=-2.6131 x+40.352, R^{2}=0.9909$, where $y$ is the $\log _{10}$ of $\mathrm{CN}$ and $x$ is the cycle threshold $(\mathrm{Ct})$ mean for the sample (10). All the amplifications were performed in duplicate by ABI 7500 fast thermal cycler (Life Technology Corporation, Carlsbad, CA) in a total volume of $13 \mu \mathrm{l}$ of reaction mix, using 
the default for the cycling conditions $\left(2 \mathrm{~min}\right.$ at $50^{\circ} \mathrm{C}$ and $10 \mathrm{~min}$ at $95^{\circ} \mathrm{C}$ followed by 40 cycles of amplification of $15 \mathrm{~s}$ at $95^{\circ} \mathrm{C}$ and $1 \mathrm{~min}$ at $60^{\circ} \mathrm{C}$ ). The PCR efficiency was monitored by using in all runs three different known amounts of cloned plasmid containing $16 \mathrm{~S}$ rDNA ' $C a$. L. asiaticus' insert, DNA samples from ' $C a$. L. asiaticus'-infected tissue (leaf petiole or psyllid), and two no template (negative control) samples (water and DNA from healthy tissue). Only plant or psyllid samples with $\mathrm{Ct}$ values $<36.0$ were considered 'Ca. L. asiaticus' positive (4,21).

Statistical analyses. Both source plant symptom development and ' $\mathrm{Ca}$. L. asiaticus' infection level were evaluated in graft-inoculated citrus trees over time (i.e., DAI). For symptom development, a generalized linear model with binomial error was used for the proportion of trees that showed symptoms at the eight different evaluation dates (11). For tree infection, we fit both linear $(y=a \mathrm{x}+$ $b)$ and asymptotic $[y=a+(b-a) \times \exp (-\exp (c) \times x)]$ functions relating ' $\mathrm{Ca}$. L. asiaticus' titer in the plant $\left(\log _{10}\right.$ of $\mathrm{CN}$ of 16SrDNA gene per gram of weight of citrus tissue) to the number of days after graft inoculation. Models were fit with function "nls" in the R programming language (11) and model fit was evaluated using Akiake's information criteria (AIC). Smaller AIC values reflect a combination of better description of the data or more parsimony.

Two sets of generalized linear models were used to test for effects on vector efficiency. A quasibinomial error distribution was assumed to account appropriately for overdispersion in the data (11). The first set of analyses considered effects of DAI and source plant infection level, both as continuous variants, on the proportion of vectors that tested positive for ' $\mathrm{Ca}$. L. asiaticus' (acquisition efficiency). Next, effects of DAI and source plant infection level were estimated for the fraction of test plants exposed to groups of psyllids that became infected with ' $C a$. L. asiaticus' (transmission efficiency).

Vector acquisition rates over time and symptom onset data were used in an additional analysis to approximate the relative number of infectious vectors that would be produced during the asymptomatic phase of ' $\mathrm{Ca}$. L. asiaticus' infection. Precise estimation of the number of infectious vectors produced in the field requires, at minimum, knowledge of (i) the number of vectors visiting plants over time, (ii) the duration of vector visits on plants, (iii) vector efficiency over different acquisition access periods, (iv) plant infection level/vector acquisition efficiency over time, and (v) pathogen incubation period in the plant. The current study in-

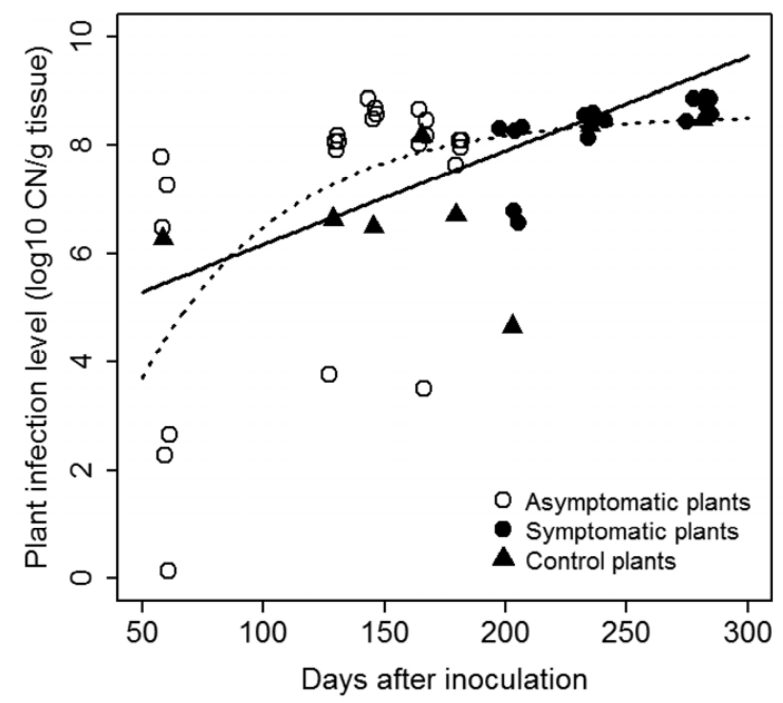

Fig. 1. Infection levels by 'Candidatus Liberibacter asiaticus' in citrus plants at different times after graft inoculation fit with both linear (solid line) and asymptotic (dashed line) functions. Positive symptomatic control plants (triangles) not included in the analysis are shown for the purposes of comparison. Some points are offset slightly for clarity. cludes estimates of these last two, in addition to vector efficiency for a 7-day AAP. If it is assumed that a constant number of vectors visit plants for a constant 7-day AAP over the duration of the incubation period, it is possible to calculate a cumulative vector exposure index. To do this, the same approach was used that is frequently applied to disease progress curves using an "area under the curve" approach (28). First, the proportion of vectors testing positive for ' $\mathrm{Ca}$. L. asiaticus' over time were fit with a power $\left(y=x^{a}\right)$, linear $(y=a \mathrm{x}+b)$, logarithmic $[y=a(\ln [x])-$ $b]$, or logistic $[y=a+(b-a) /(1+\exp [(c-x) / d])]$ function. Then, the proportional acquisition for consecutive 1-week intervals between 0 and 199 DAI was summed for each of these fitted functions. The resulting sum is a reflection of the cumulative likelihood that vectors will successfully acquire ' $C a$. L. asiaticus' over the duration of the asymptomatic phase per vector-week visitation.

\section{RESULTS}

' $\mathrm{Ca}$. L. asiaticus' source plants: graft transmission efficiency, symptom onset, and infection level. Morphological parameters such as tree height and the presence of young shoots and leaves were used to select the trees to be used as source plants in each acquisition assay, in order to standardize phenological characteristics that could influence vector behavior and transmission efficiency. ' $\mathrm{Ca}$. L. asiaticus' was detected in the totality of the selected plants as a consequence of the high transmission efficiency by grafting. None of the negative control plants tested positive for ' $\mathrm{C} a$. L. asiaticus', whereas the symptomatic plants (positive controls) were all positive (Fig. 1).

For the graft-inoculated source trees, there was a significant effect of DAI on the proportion expressing symptoms $\left(\chi^{2}=55.64\right.$, df $=1, P<0.0001)$. No symptoms were apparent prior to 200 DAI but all plants from day 200 onward showed symptoms consistent with HLB (Fig. 1). Plant infection levels (i.e., ' $C a$. L. asiaticus' titer or concentration) increased in a saturating manner from an average of $\approx 10^{4} \mathrm{CN} / \mathrm{g}$ of tissue at the first sampling date to $\approx 10^{8} \mathrm{CN}$ for trees sampled $200 \mathrm{DAI}$ or later (Fig. 1). Based on AIC rankings, the asymptotic function better explained infection levels (i.e., lower AIC score) than did the linear function, with an estimated upper limit to infection of $\approx 10^{8.5} \mathrm{CN} / \mathrm{g}$ of tissue (Table 1). Symptom status was not evaluated as a main causal factor for plant infection level (' $\mathrm{Ca}$. L. asiaticus' titer) because it is confounded with DAI (i.e., symptoms uniformly began at 200 DAI) and trees with higher ' $\mathrm{Ca}$. L. asiaticus' titer earlier than 200 DAI did not show HLB-like symptoms. However, in general, symptomatic plants tended to have higher infection levels than asymptomatic plants (mean \pm standard deviation: $8.31 \pm 0.65$ versus $6.98 \pm 2.43 \log _{10} \mathrm{CN} / \mathrm{g}$ of tissue).

Pathogen acquisition and transmission. Vectors failed to acquire and transmit ' $C a$. L. asiaticus' from any of the negative control plants. This included 0 of 64 psyllid groups tested from across the eight acquisition assays dates and 0 of 93 test plants exposed to psyllid groups.

For graft-inoculated source trees, there was high variability in the frequency of psyllid acquisition (Fig. 2). There was a significant and positive effect of the number of days after graft inoculation on the fraction of psyllids that tested positive for ' $\mathrm{Ca}$. L. asiaticus' $\left(\chi^{2}=38.75\right.$, df $\left.=1, P=0.004\right)$. On average, the fraction of psyllids testing positive for ' $\mathrm{Ca}$. L. asiaticus' increased from $\approx 20 \%$ near 60 DAI to $>80 \%$ at 280 DAI (Fig. 2). However, a full model that evaluated simultaneously the effects of DAI and source plant infection level was compared with reduced models that removed interactive and main effects of DAI and source plant infection level, using analysis of deviance tests (11). The results of that model simplification indicate that only the main effect of source plant infection level was required to adequately describe psyllid acquisition of ' $\mathrm{Ca}$. L. asiaticus'. This suggests that there was substantial collinearity between DAI and source infection 
level, with underlying infection level being more directly causally related to acquisition success. Source plant infection level was positively and significantly related to the fraction of psyllids that tested positive for ' $C a$. L. asiaticus' $\left(\chi^{2}=55.17\right.$, df $=1, P=$ $0.001)$. With the exception of one grouping, psyllids on source plants with infection levels below $10^{6} \mathrm{CN} / \mathrm{g}$ of tissue resulted in no acquisition. Conversely, at the highest infection levels, psyllids acquired ' $\mathrm{Ca}$. L. asiaticus' nearly $70 \%$ of the time (Fig. 3).

The evaluation by qPCR of test plants exposed to psyllids showed very low overall transmission rates. Just 3 of 419 test plants become infected with ' $\mathrm{Ca}$. L. asiaticus' after exposure to psyllids that had been confined previous on graft-inoculated source plants, and 1 of 87 plants exposed to psyllids confined on positive control plants. There were significant effects of neither original source plant infection level $\left(\chi^{2}=1.77\right.$, $\left.\mathrm{df}=1, P=0.261\right)$ nor DAI $\left(\chi^{2}=2.35\right.$, df $\left.=1, P=0.236\right)$.

In the analysis of the relative infectiousness of psyllids during the asymptomatic phase, the logarithmic model predicted the lowest relative production of infectious vectors whereas the highest, the power model, predicted nearly $80 \%$ more (Table 2 ). Yet, based on AIC values, the linear model provided the best fit of the four models considered. Thus, the preferred model predicts that, for each week-long vector visit over $\approx 29$ consecutive weeks on a ' $C a$. L. asiaticus'-infected citrus, nearly 10 infectious vectors will be produced (Table 2). In other words, there is substantial potential for psyllids to acquire ' $\mathrm{Ca}$. L. asiaticus' during the asymptomatic phase of infection.

\section{DISCUSSION}

Although Koch's postulate remains incomplete, multiple lines of evidence point to ' $\mathrm{Ca}$. L. asiaticus' as playing a causal role in HLB symptomology $(12,16,37)$. Thus far, D. citri is recognized as the primary vector of this bacterium (20). Prior experiments have documented effects of factors such as psyllid development stage and AAPs or IAPs on the efficiency of $D$. citri as a vector of ' $C a$. L. asiaticus' $(8,25,31)$. Comparatively less attention has been paid to the underlying effects of source plant infection levels in driving psyllid efficiency. In this study, vector competence was assessed as both the proportion of successful acquisition or inoculation events by adult psyllids over a gradient in ' $\mathrm{Ca}$. L. asiaticus' infection levels in citrus trees and over time after graft inoculation of this pathogen. These data allow estimates of important epidemiological parameters such as duration of latent infection and incubation period in citrus, and minimum host infection level required for pathogen acquisition.

The vast majority of grafting events resulted in ' $\mathrm{Ca}$. L. asiaticus'-infected plants. The analyzed samples showed an increase of ' $C a$. L. asiaticus' infection level over time, which is expected given prior results (10). More notable is that the progress of infection was best fit by an asymptotic model, suggesting an upper limit to ' $\mathrm{Ca}$. L. asiaticus' infection in citrus-even though young, asymptomatic leaves were used for all pathogen quantifications. It is also interesting to note that the high infection levels were observed at approximately the same time, 200 DAI, when HLB disease symptoms first began to manifest. Considering that graft inoculation is likely to introduce substantially higher initial inoculum supplies into citrus trees than vectors do, it is appropriate to view this as being a relatively long incubation period. Such a conclusion is certainly consistent with anecdotal observations from the field, which suggest that ' $\mathrm{Ca}$. L. asiaticus' infections may develop for upward of several months or a year before HLB symptoms occur $(17,29)$.

Associated with increasing ' $\mathrm{Ca}$. L. asiaticus' infection levels over time, there were also increasing acquisition rates by psyllids. Although time-specific changes in plant condition may have influenced acquisition success, most of the overall effect of time since acquisition stems from underlying increases in bacterial titer at later dates. This conclusion is supported by the statistical analyses which found more important effects of source plant infection level than the direct effect of time since inoculation. Moreover, for two of the eight evaluation dates plus the symptomatic controls, within-group infection level (source plants with same age) was positively and significantly related to acquisition frequency (M. P. Daugherty, data not shown). It is worth noting that the influence of plant age or condition on acquisition efficiency was minimized in our study, because we standardized the age of citrus shoots offered to the psyllids during acquisition. Although there was not a clear overall threshold requirement for ' $\mathrm{Ca}$. L. asiaticus' acquisition, source plants with ' $\mathrm{Ca}$. L. asiaticus' DNA at $<10^{6} \mathrm{CN} / \mathrm{g}$ of plant tissue resulted in low proportions of vectors acquiring the pathogen, except for one plant with $\approx 10^{3}$ $\mathrm{CN} / \mathrm{g}$ of plant tissue, in which seven of eight replicates resulted in successful acquisition (Fig. 3).

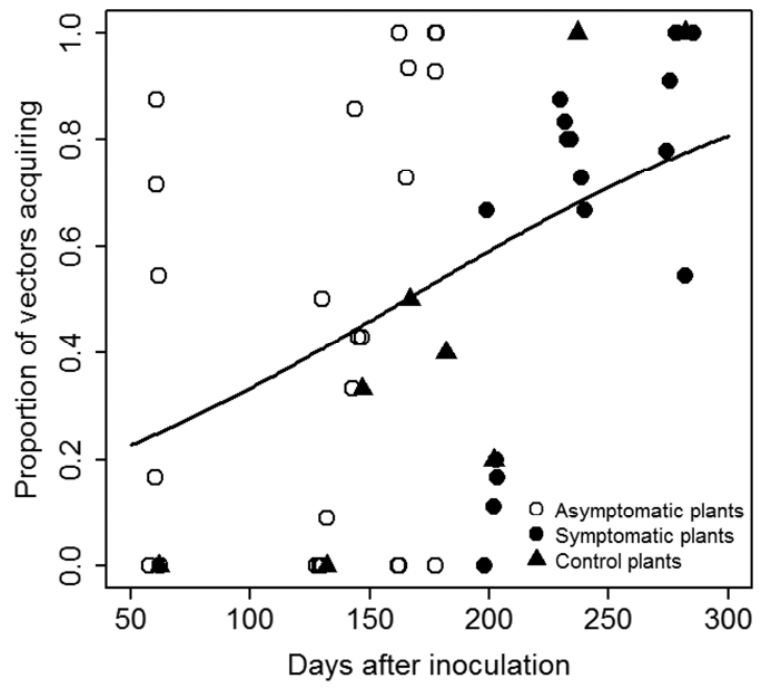

Fig. 2. 'Candidatus Liberibacter asiaticus' acquisition frequency by Diaphorina citri at different times after graft inoculation. The line shows the fit of the generalized linear model. Some points are offset slightly for clarity.

TABLE 1. Model comparison for 'Candidatus Liberibacter asiaticus' infection level within citrus plants ( $\log _{10} \mathrm{CN} / \mathrm{g}$ of tissue) as a function of days after graft inoculation

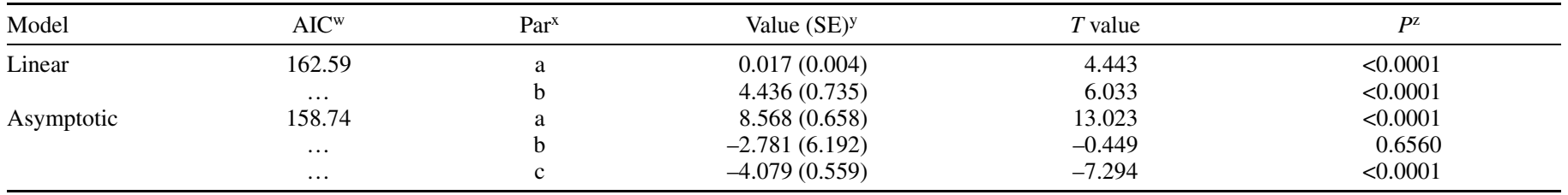

\footnotetext{
w Akiake's information criteria (AIC). Smaller AIC values reflect a combination of better description of the data or more parsimony.

${ }^{x}$ Estimated model parameters. See text for full model equations. Parameters may have different meanings in different models.

y $\mathrm{SE}=$ standard error.

y $P$ values $<0.05$ indicate the model parameter differs significantly from zero.
} 
To our knowledge, this is the first documentation of ' $\mathrm{Ca}$. L. asiaticus' acquisition by $D$. citri as a function of host infection level. Consistent with the positive relationship presented here, Hill and Purcell (22) observed that high Xylella fastidiosa infection levels within grapevines were strongly predictive of successful acquisition by sharpshooters. On the other hand, in another vector-borne bacterial disease (zebra chip disease of potato, associated with ' $\mathrm{Ca}$. L. solanacearum'), the proportion of vectors that acquired the pathogen was independent of bacterial titer within plant tissue (32). However, it is worth noting that that study did not systematically evaluate acquisition rate on the same plant tissue type over a gradient of infection levels. Regardless, aside from this small set of studies, empirical data evaluating the relationship between within-host bacterial infections and vector efficiency are scarce. Given the potential for this relationship to impact pathogen acquisition and spread, further investigation in other plant pathosystems is certainly warranted.

Pathogen acquisition by $D$. citri was also associated with the duration of infection. This effect is largely attributable to the already-noted increase in infection levels in graft-inoculated trees over time. However, it is worth noting how soon after inoculation that acquisition was possible, a metric that is known as the host latent infection period. Epidemiological theory suggests that the sooner infected hosts develop to become competent sources of the pathogen, the greater the potential for disease outbreak (27).

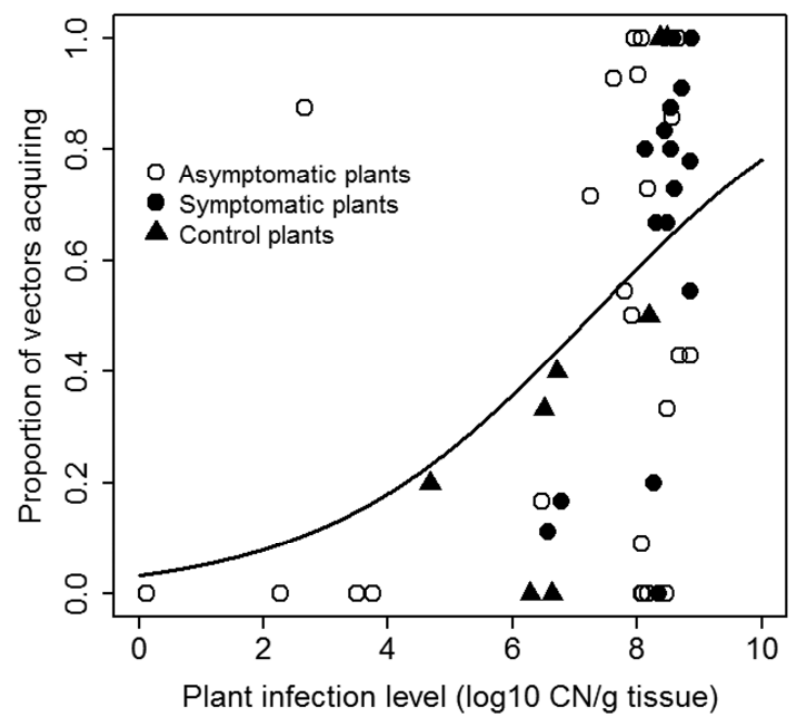

Fig. 3. 'Candidatus Liberibacter asiaticus' acquisition frequency by Diaphorina citri among different source plant infection levels by the bacterium. The line shows the fit of the generalized linear model.
Results from the current study suggest that, though not guaranteed, D. citri can acquire from graft-inoculated citrus within 2 months. Given that this was the first vector introduction time, it is possible that the latent infection period for these trees was even shorter. In fact, based on the best-fit model from the analysis of relative infectiousness during the asymptomatic phase (Table 2), it is possible for acquisition to occur immediately after trees become infected-albeit at a very low frequency (i.e., <9\%). This result is problematic from a disease management perspective because it means that trees may be sources of infectious vectors well before (i.e., $\geq 4$ months prior) it is apparent that a tree is diseased. In other words, because latent infection period in citrus is much shorter than the incubation period, visual symptoms alone may be inadequate for identifying diseased trees early enough for rouging to be fully effective.

Although acquisition was positively related to the bacterial titer in the plants (Fig. 3) and the time elapsed after inoculation (Fig. 2 ), there was substantial variability in the acquisition rates. The uneven distribution of pathogen within plants (35) and also within branches (14) may explain some of this variability. Failures to acquire were observed more frequently before the occurrence of first HLB symptoms, when ' $\mathrm{Ca}$. L. asiaticus' infections may not yet be fully systemic. Because multiple independent source plants per block were assayed over time, differences in acquisition efficiencies also may be linked to features associated with the physiology of host plants (31). Also, the lack of a straight relationship between bacterial titer and symptom expression was also observed (34), with $\mathrm{Ct}$ values of 22.3 to 26.1 and 23.2 to 25.0 for asymptomatic tissues and symptomatic tissues, respectively.

Contrary to the relatively high rates of ' $\mathrm{Ca}$. L. asiaticus' acquisition by psyllids adults (nearly $60 \%$ overall, range of 7.7 to $92 \%$ ), inoculation efficiency was markedly lower, $<1 \%$ overall. This result may be explained by several factors. A likely explanation was the use of $D$. citri adults for both bacterial acquisition and inoculation in the transmission assays; a prior study showed efficient transmission of ' $\mathrm{Ca}$. L. asiaticus' by $\mathrm{D}$. citri adults only when bacterial acquisition occurred in the nymphal stage (25). Alternatively, it could stem from differences among $D$. citri populations, which can vary in their efficiency $(25,31)$; differences in strains of symbiotic bacteria (19); or differences in transmissibility of distinct ' $\mathrm{Ca}$. L. asiaticus' strains, which are genetically diverse $(9,26,39)$. Regardless, although such a low inoculation rate is consistent with the low transmission efficiency of ' $\mathrm{Ca}$. L. asiaticus' reported in Florida (31), it is perplexing given the observations of rapid spread by this disease in the field.

The probability of successfully managing HLB via vector control and rouging of diseased trees depends strongly on grove size and proximity to unmanaged groves (5), suggesting an important role for psyllids in pathogen spread. Results of this study highlight the substantial potential for psyllids to acquire ' $\mathrm{Ca}$. L. asiaticus' from

TABLE 2. Model comparison for 'Candidatus Liberibacter asiaticus' acquisition by vectors during the asymptomatic phase of plant infection

\begin{tabular}{|c|c|c|c|c|c|c|}
\hline Model & $\mathrm{AIC}^{\mathrm{v}}$ & Relative infectiousness ${ }^{\mathrm{w}}$ & $\operatorname{Par}^{\mathrm{X}}$ & Value $(\mathrm{SE})^{\mathrm{y}}$ & $T$ value & $P^{\mathrm{z}}$ \\
\hline Power & 43.24 & 16.908 & a & $-0.127(0.024)$ & -5.329 & $<0.0001$ \\
\hline \multirow[t]{2}{*}{ Linear } & 34.203 & 9.902 & $\mathrm{a}$ & $0.002(0.001)$ & 2.979 & 0.0050 \\
\hline & $\ldots$ & $\ldots$ & $\mathrm{b}$ & $0.088(0.155)$ & 0.564 & 0.5758 \\
\hline \multirow[t]{2}{*}{ Logarithmic } & 36.807 & 9.462 & $\mathrm{a}$ & $0.297(0.133)$ & 2.433 & 0.0198 \\
\hline & $\ldots$ & $\ldots$ & $\mathrm{b}$ & $0.984(0.621)$ & 1.585 & 0.1213 \\
\hline \multirow[t]{4}{*}{ Logistic } & 36.262 & 10.99 & $\mathrm{a}$ & $0.332(0.177)$ & 1.872 & 0.0693 \\
\hline & $\ldots$ & $\ldots$ & $\mathrm{b}$ & $1.109(1.321)$ & 0.840 & 0.4064 \\
\hline & $\ldots$ & $\ldots$ & $\mathrm{c}$ & $244.150(151.014)$ & 1.617 & 0.1147 \\
\hline & $\ldots$ & $\ldots$ & $\mathrm{d}$ & $40.369(75.657)$ & 0.534 & 0.5969 \\
\hline
\end{tabular}

v Akiake's information criteria (AIC). Smaller AIC values reflect a combination of better description of the data or more parsimony.

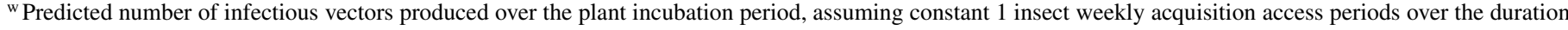
of the incubation period.

${ }^{x}$ Estimated model parameters. See text for full model equations. Parameters may have different meanings in different models.

y $\mathrm{SE}=$ standard error.

${ }^{\mathrm{z}} P$ values $<0.05$ indicate the model parameter differs significantly from zero. 
infected trees prior to symptom onset. However, it is also clear that the rate of ' $\mathrm{Ca}$. L. asiaticus' transmission to citrus plants by individual $D$. citri that acquired the bacteria during the adult phase is low, even though a much higher percentage of psyllids were infected. Thus, adequate control may be achievable with an aggressive combination of vector control and removal of infected trees-especially if earlier detection can be achieved.

\section{ACKNOWLEDGMENTS}

This research was funded by the Citrus Research and Development Foundation (project number NAS-126), Florida. H. D. Coletta-Filho and J. R. S. Lopes acknowledge the National Council for Scientific and Technological Development (CNPq)/Brazil for a fellowship support. We thank F. Perina, Jr. for help with the acquisition assays and K. Licatta and S. Dorta for the qPCR analysis.

\section{LITERATURE CITED}

1. Agrios, G. N. 2004. Plant Pathology, 5th ed. Elsevier Academic Press, San Diego, CA.

2. Almeida, R. P. P. 2008. Vector-borne diseases: Understanding the environmental, human health, and ecological connections. Pages 70-77 in: Workshop Summary (Forum on Microbial Threats). The National Academies Press, Washington, D.C.

3. Ammar, E. D., Shatters, R. G., Jr., and Hall, D. G. 2011. Localization of 'Candidatus Liberibacter asiaticus', associated with citrus huanglongbing disease, in its psyllid vector using fluorescence in situ hybridization. J. Phytopathol. 159:726-734.

4. Ammar, E. D., Shatters, R. G, Jr., Lynch, C., and Hall, D. G. 2011. Detection and relative titer of 'Candidatus Liberibacter asiaticus' in the salivary glands and alimentary canal of Diaphorina citri (Hemiptera: Psyllidae) vector of citrus huanglongbing disease. Ann. Entomol. Soc. Am. 104:526-533.

5. Belasque, J., Bassanezi, R. B., Yamamoto, P. T., Ayres, A. J., Tachibana, A., Violante, A. R., Tank, A., Di Giorgi, F., Tersi, F. E. A., Menezes, G. M., Dragone, J., Jank, R. H., and Bove, J. M. 2010. Lessons from huanglongbing management in São Paulo State, Brazil. J. Plant Pathol. 92:285-302.

6. Bonani, J. P., Fereres, A., Garzo, E., Miranda, M. P., Appezzato-daGloria, B., and Lopes, J. R. S. 2010. Characterization of electrical penetration graphs of the Asian citrus psyllid, Diaphorina citri, in sweet orange seedlings. Entomol. Exp. Appl. 134:35-49.

7. Bové, J. M. 2006. Huanglongbing: A destructive, newly-emerging, century-old disease of citrus. J. Plant Pathol. 88:7-37.

8. Capoor, S. P., Rao, D. G., and Viswanath, S. M. 1974. Greening disease of citrus in the Deccan Trap Country and its relationship with the vector, Diaphorina citri Kuwayama. Pages 43-49 in: Proc. 6th Conf. Int. Organ. Citrus Virol. L. G. Weathers and M. Cohen, eds. IOCV, Richmont, CA.

9. Chen, J., Deng, X., Sun, X., Jones, D., Irey, M., and Civerolo, E. 2010. Guangdong and Florida populations of 'Candidatus Liberibacter asiaticus' distinguished by a genomic locus with short tandem repeats. Phytopathology 100:567-572.

10. Coletta-Filho, H. D., Carlos, E. F., Alves, K. C. S., Pereira, M. A. R., Boscariol-Camargo, R. L., de Souza, A. A., and Machado, M. A. 2010. In planta multiplication and graft transmission of 'Candidatus Liberibacter asiaticus' revealed by real-time PCR. Eur. J. Plant Pathol. 126:53-60.

11. Crawley, M. J. 2009. The R Book. John Wiley and Sons, West Sussex, England.

12. Duan, Y., Zhou, L., Hall, D. G., Li, W., Doddapaneni, H., Lin, H., Liu, L., Vahling, C. M., Gabriel, D. W., Williams, K. P., Dickerman, A., Sun, Y., and Gottwald, T. 2009. Complete genome sequence of citrus huanglongbing bacterium, 'Candidatus Liberibacter asiaticus' obtained through metagenomics, Mol. Plant-Microbe Interact. 22:1011-1020.

13. Fernandez-Calvino, L., López-Abella, D., and López-Moya, J. J. 2007. Integrated management of insect borne viruses by means of transmission interference as an alternative to pesticides. Pages 269-293 in: General Concepts in Integrated Pest and Disease Management. Springer Verlag, New York.

14. Folimonova, S. Y., Robertson, C. J., Garnsey, S. M., Gowda, S., and Dawson, W.O. 2009. Examination of the responses of different genotypes of citrus to huanglongbing (citrus greening) under different conditions. Phytopathology 99:1346-1354.

15. Froissart, R., Doumayrou, J., Vuillaume, F., Alizon, S., and Michalakis, Y. 2010. The virulence-transmission trade-off in vector-borne plant viruses: A review of (non-) existing studies. Phil. Trans. R. Soc. B. 365:1907-1918.

16. Garnier, M., Danel, N., and Bové, J. M. 1984. The greening organism is a Gram negative bacterium. Pages 115-124 in: Proc. 9th Conf. Int. Organ. Citrus Virol. L. W. Timmer, S. M. Garnsey, and L. Navarro, eds. IOCV,
Riverside, CA.

17. Gottwald, T. R. 2010. Current epidemiological understanding of citrus huanglongbing. Annu. Rev. Phytopathol. 48:119-139.

18. Gottwald, T. R, da Graça, J. V., and Bassanezi, R. B. 2007. Citrus Huanglongbing: the pathogen and its impact. Plant Health Progress. Onine publication. doi:10.1094/PHP-2007-0906-01-RV

19. Guidolin, A. S., and Cônsuli, F. L. 2013. Molecular characterization of Wolbachia strains associated with the invasive Asian citrus psyllid Diaphorina citri in Brazil. Microbiol. Ecol. 65:475-486.

20. Halbert, S. E., and Manjunath, K. L. 2004. Asian citrus psyllids (Sternorrhyncha: Psyllidae) and greening disease in citrus: A literature review and assessment of risk in Florida. Fla. Entomol. 87:330-353.

21. Hilf, M. E. 2011. Colonization of citrus seed coats by 'Candidatus Liberibacter asiaticus': Implications for seed transmission of the bacterium. Phytopathology 101:1242-1250.

22. Hill, B. L., and Purcell, A. H. 1997. Populations of Xylella fastidiosa in plants required for transmission by an efficient vector. Phytopathology 87:1197-1201

23. Huang, C. H. M., Tsai, Y., and Wang, C. L. 1984. Transmission of citrus likubin by a psyllid, Diaphorina citri. J. Agric. Res. China 33:65-72.

24. Hung, T. H., Hung, S. C., Chen, C. N., Hsu, M. H., and Su, H. J. 2004. Detection by PCR of 'Candidatus Liberibacter asiaticus', the bacterium causing citrus huanglongbing in vector psyllids: Application to the study of vector-pathogen relationships. Plant Pathol. 53:96-102.

25. Inoue, H., Ohnishi, J., Ito, T., Tomimura, K., Miyata, S., Iwanami, T., and Ashihara, W. 2009. Enhanced proliferation and efficient transmission of 'Candidatus Liberibacter asiaticus' by adult Diaphorina citri after acquisition feeding in the nymphal stage. Ann. Appl. Biol. 155:29-36.

26. Islam, M.-S., Glynn, J. M., Bai, Y., Duan, Y. P., Coletta-Filho, H. D., Kuruba, G., Civerolo, E. L., and Lin, H. 2012. Multilocus microsatellite analysis of 'Candidatus Liberibacter asiaticus' associated with citrus huanglongbing worldwide. BMC Microbiol. 12:39.

27. Jeger, M. J., van den Bosch, F., Madden, L. V., and Holt, J. 1998. A model for analyzing plant-virus transmission characteristics and epidemic development. IMA J. Math. Appl. Med. Biol. 15:1-18.

28. Madden, L. V., Hughes, G., and van den Bosch, F. 2007. The Study of Plant Disease Epidemics. American Phytopathological Society, St. Paul, MN

29. Manjunath, K. L., Halbert, S. E., Ramadugu, C., Webb, S., and Lee, R. F. 2008. Detection of 'Candidatus Liberibacter asiaticus' in Diaphorina citri and its importance in the management of citrus huanglongbing in Florida. Phytopathology 98:387-396.

30. Murray, M., and Thompson, W. F. 1980. Rapid isolation of highmolecular-weight plant DNA. Nucleic Acids Res. 8:4321-4325.

31. Pelz-Stelinski, K. S., Brlansky, R. H., Ebert, T. A., and Rogers, M. E. 2010. Transmission parameters for Candidatus Liberibacter asiaticus by Asian citrus psyllid (Hemiptera: Psyllidae). J. Econ. Entomol. 103:1531-1541.

32. Rashed, A., Nash, T., Paetzold, L., Workneh, F., and Rush, C. M. 2012. Transmission efficiency of 'Candidatus Liberibacter solanacearum' and potato zebra chip disease progress in relation to pathogen titer, vector numbers, and feeding sites. Phytopathology 102:1079-1085.

33. Sparagano, O. A. E., and de Luna, C. J. 2008. From population structure to genetically engineered vectors: New ways to control vector-borne diseases? Infect. Genet. Evol. 8:520-525.

34. Tatineni, S., Sagaram, U. S., Gowda, S., Robertson, C. J., Dawson, W. O., Iwanami, T., and Wang, N. 2008. In planta distribution of 'Candidatus Liberibacter asiaticus' as revealed by polymerase chain reaction (PCR) and real-time PCR. Phytopathology 98:592-599.

35. Teixeira, D. C., Saillard, C., Couture, C., Martins, E. C., Wulff, N. A, Eveillard-Jagoueix S., Yamamoto, P. T., Ayres, A. J., and Bove, J. M. 2008. Distribution and quantification of Candidatus Liberibacter americanus, agent of huanglongbing disease of citrus in Sao Paulo State, Brazil, in leaves of an affected sweet orange tree as determined by PCR. Mol. Cell. Probes 22:139-150.

36. Tsai, J. H., Wang, J. J., and Liu, Y. H. 2002 Seasonal abundance of the Asian citrus psyllid, Diaphorina citri (Homoptera: Psyllidae) in southern Florida. Fla. Entomol. 85:446-451.

37. Tyler, H. L., Roesch, F. L.W., Gowda, S., Dawson, W. O., and Triplett, E. W. 2009. Confirmation of the sequence of 'Candidatus Liberibacter asiaticus' and assessment of microbial diversity in huanglongbinginfected citrus phloem using a metagenomic approach. Mol. PlantMicrobe Interact. 22:1624-1634

38. Xu, C. F., Xia, Y. H., Li, K. B., and Ke, C. 1988. Further study of the transmission of citrus huanglungbin by a psyllid, Diaphorina citri Kuwayama. Pages 243-248 In: Proc. 10th Conf. Int. Org. Citrus Virol. L. W. Timmer, S. M. Garnsey, and L. Navarro, eds. IOCV, Valencia, Spain.

39. Zhou, L., Powell, C. A., Hoffman, M. T., Li, W., Fan, G., Liu, B., Lin, H., and Duan, Y. 2011. Diversity and plasticity of the intracellular plant pathogen and insect symbiont 'Candidatus Liberibacter asiaticus' as revealed by hypervariable prophage genes with intragenic tandem repeats. Appl. Environ. Microbiol. 77:6663-6673. 